\title{
Thermal Performance of Fined Plate Mini-Channel Heat Sink
}

\author{
Suliman Mohamed Mohamed Ali ${ }^{1}$, Waleedfekryfaris ${ }^{2}$, Ahmad Faris Ismail $^{2}$, \\ Andsher Afghan Khan ${ }^{2}$ \\ ${ }^{1}$ Research Scholar, Department Of Mechanical Engineering, Faculty Of Engineering, International Islamic \\ University Malaysia (IIUM), Malaysia \\ ${ }^{2}$ Professor, Department Of Mechanical Engineering, Faculty Of Engineering, International Islamic University \\ Malaysia (IIUM), Malaysia
}

\begin{abstract}
This paper presents fined plate minichannel heat sink numerically under forced convection. Two geometries, flat plate and fined plat heat sinks have been drawn by solidworks, then imported to Starccm+ for simulation. The plate was $45 \mathrm{~mm}$ width and $55 \mathrm{~mm}$ length and the fined heat sink has fins with $3 \mathrm{~mm}$ height and $1 \mathrm{~mm}$ thickness. Source load $325 \mathrm{~W}$ at the bottom of heat sink ad different volumetric flow rate 0.5, 0.75 and 1 liter per minute are used to simulate the microprocessor. The results have shown that fins heat sink has more heat transfer rate, 194.3 watts at lliter per minute. Moreover, thermal resistance and base temperature reduced $58 \%$ and $30.7 \%$ compared to flat plate respectively. The results have shown excellent agreement with published experiments.
\end{abstract}

Keywords: mini-channel heat sink, flat plate, fined plate heat sink.

\section{Introduction}

Fins used widely to conduct heat generated at the surface, fluid, air or liquid pass through fins to remove heat easily. Fins heat sinks are applied to electronics and gas engines cooling. Researchers studied the height, thickness and shape and size of the fined plate heat sink.Kim et al [1] presented a vertical plate-fin heat sinks under natural convection in a fully-developed-flow regime. Lin et al [2] used vertical planar fin array in conventional heat sinks for CPU cooling experimentally. They utilized an oblique planar fins heat sink to improve the overall performance of the heat sink. Wang et al [3] proposed a novel cannelure fin structure under cross flow condition air-cooled heat sink. Pang [4] designed a hybrid PV/TE system integrating a thermoelectric (TE), photovoltaic (PV) to evaluate the thermal behaviors and the cooling performance. Yi Li et al [5] assessed the performance of plate-fin heat sinks in a cross flow. Shen et al [6] carried out experimental and numerical study of the orientation effects on the fluid flow and heat transfer of rectangular fin heat sinks under natural convection conditions. Jang et al [7] examined the orientation effect for a cylindrical heat sink used to cool an LED light bulb numerically. Kwon Kim [8] studied thermal performance of a vertical plate-fin heat sink under natural convection. It was optimized for the case in which the fin thickness varied in the direction normal to the fluid flow. Sohel et al [9] experimentally investigated the thermal performances of a mini-channel heat sink for cooling of electronics using nanofluid coolant instead of pure water.Ho et al [10]worked, experimental to explore the forced convective heat transfer performance of using $\mathrm{Al}_{2} \mathrm{O}_{3}$ /water nano-fluid to replace the pure water as the coolant in a copper mini-channel heat sink.Hashemi et al [11] reported numerical solution and analytical solution for fully developed velocity profile in a miniature plate fin heat sink with $\mathrm{SiO}_{2}$-water nanofluid as coolant. [12]Used a base fluid made of $75 \%$ water and $25 \%$ of ethylene glycol. $\mathrm{TiO} 2, \mathrm{SiO} 2$ and $\mathrm{Al} 2 \mathrm{O} 3$ nanoparticles with different volume loading in the base fluid was tested to achieve the lowest operating temperature of a quad-core processor. SaadAyubJajja et al [13] investigated five different heat sinks with fin spacing's of $0.2 \mathrm{~mm}, 0.5 \mathrm{~mm}, 1.0 \mathrm{~mm}$, and $1.5 \mathrm{~mm}$ along with a flat plate heat sink. The base temperature and thermal resistance of the heat sinks were found to drop by decreasing the fin spacing and by increasing volumetric flow rate of water. More temperature drops to $40.5 \mathrm{C}$ at spacing $0.2 \mathrm{~mm}$, volumetric flow rate equal 1 LPM.

This article carried out a numerical study on flat plate and fined plate mini-channel heat sinks under forced convection. As the fins have been found very important for the heat sink [1], the particular focus of this study was the influence of heat sink fins on heat transfer and thermal resistance of fined heat sinks. Thermal performance of fined heat sinks was compared with flat plate under a given flow rate and heat source load conditions. Reynolds number ranges from 400 to 2000. Based on computational results, different physical flow phenomena in flat plate and finned plat heat sink were shown, and local temperature distributions were discussed in detail to explain the overall heat transfer behavior. Finally, the influence fins heat sink was 
discussed. For validation the numerical results have been compared with and experimental done by AyubJajja et al [13].

\section{Meshing study}

To understand the sensitivity of the heat sink grid, four different grids, 38576 coarse grids cells, 446329 fine grids cells and 756549 and 1088726 very fine grids cells were used to check the stability of the grids. Best grids have been used within the heat sink in order to measure the fluid flow and heat transfer characteristics. Surface temperature has been used as measurement. Figure 1 shows the surface temperature with grid cells.

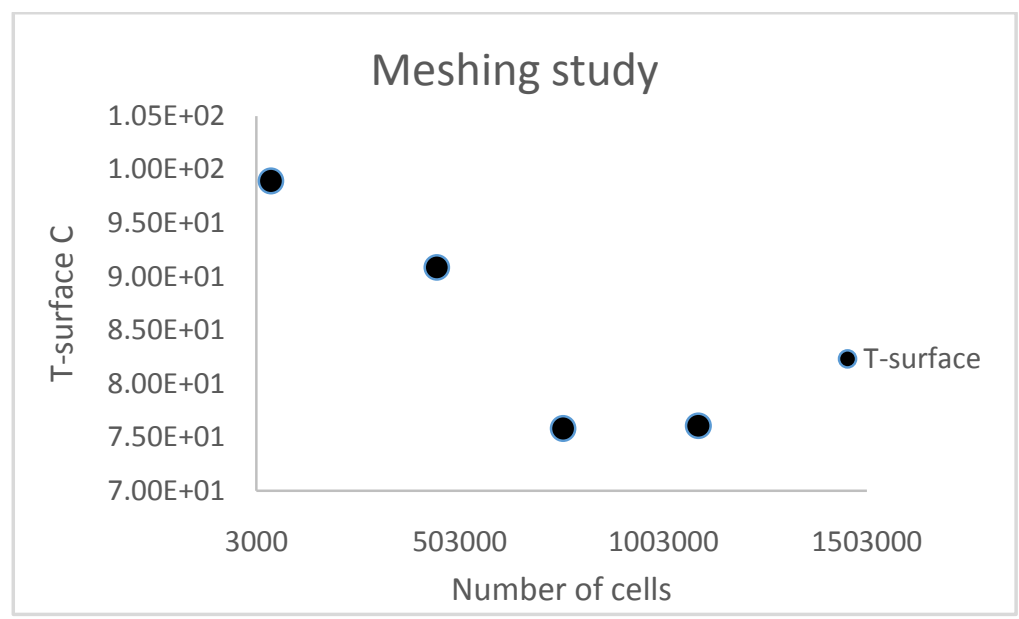

Figure 1: Meshing independence study

\section{Geometry and physics model}

Two geometries have been drawn using solidworks premium 2016 and the simulation has been performed using starccm+ 10.6. The heat source is assumed at the bottom of the mini-channel heat sink. $325 \mathrm{~W}$ power supplieswere used with each heat sink configuration. The flat heat sink dimensions is $55 \mathrm{~mm}$ width, 45 $\mathrm{mm}$ length and $3 \mathrm{~mm}$ height, the fins has $1 \mathrm{~mm}$ thickness, $55 \mathrm{~mm}$ length and $3 \mathrm{~mm}$ height. Figure 2 show the flat plate and fined plate mini-channel heat sinks.
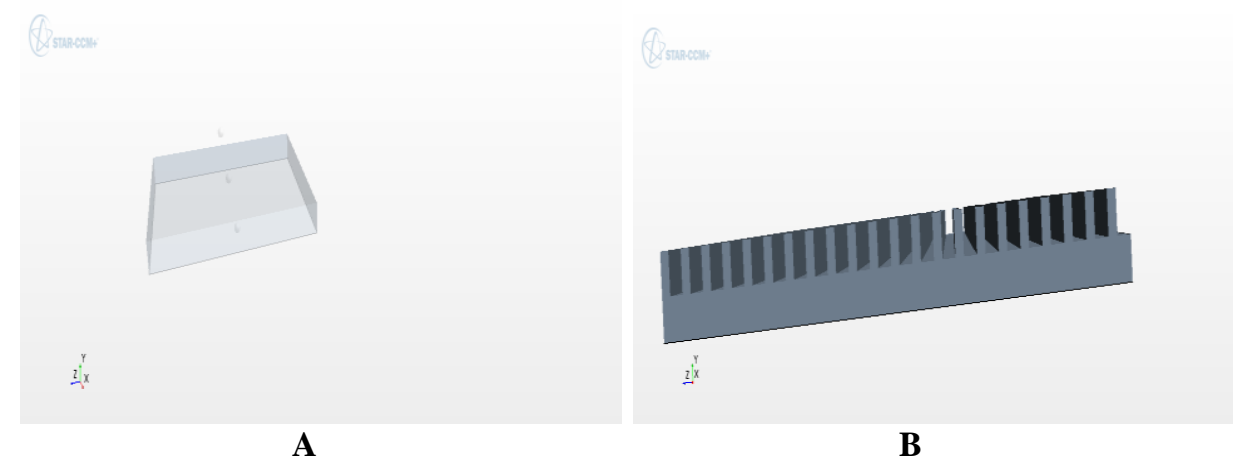

Figure 2: Flat plate (A)and fined plate (B)minichannel heat sinks.

\subsection{Heat sink and temperature drop}

\section{Results And Discussion}

Figure 1 presents the difference in base temperature produced by finned heat sink in comparison to the flat plate heat sink. The greatest base temperature drop of $30.3^{\circ} \mathrm{C}$ at $0.5 \mathrm{LPM}$ resulted when $1.5 \mathrm{~mm}$ fin spacing heat sink was used. As a result of using fined plate mini-channel heat sink, the lowest base drop temperature of $23.8^{\circ} \mathrm{C}$ was achieved at a flow rate of $1 \mathrm{LPM}$. 


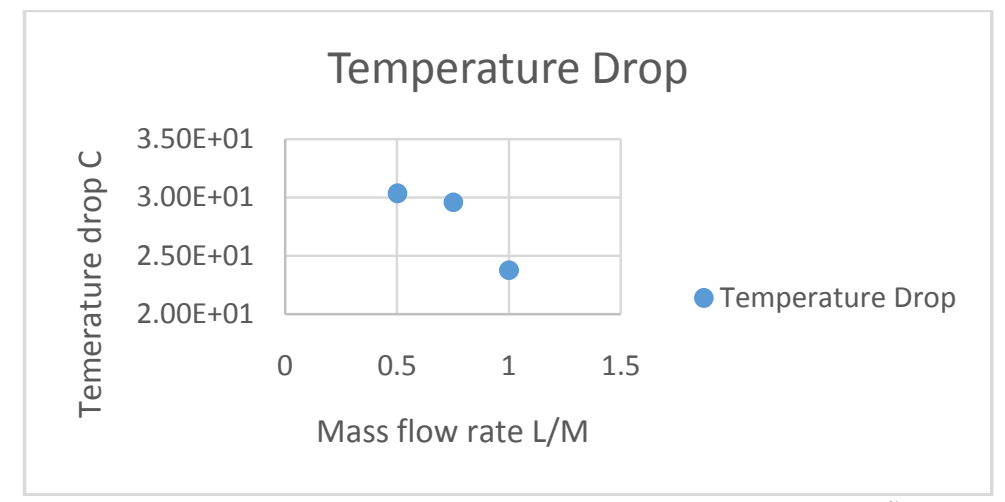

Figure 3: Comparison of temperature drop with volumetric flowrate.

\subsection{Heat sink and heat transfer rate}

Fig. 4indicates a comparison of heat transfer rate to the coolant with volumetric flow rate. Even with the smaller magnitude of volumetric flow rate for the finned sinks, they indicated significantly higher heat transfer rates in comparison of flat heat sink which was due to the fact of significant area enhancement, 2.3 in comparison of flat heat sink for $1.5 \mathrm{~mm}$ finned heat sinks, respectively. It can be seen that a finned heat sink at flow rate of $1 \mathrm{~L}$ per minute was able to remove $194 \mathrm{~W}$ of heat (about $60 \%$ of the total source load which was $325 \mathrm{~W}$ ). The minimum heat removed found by the flat sink at a flow rate of $0.5 \mathrm{~L}$ per minute was $162 \mathrm{~W}$ (about $50 \%$ of the source power). The heat rate errorof numerical simulation was always found to be within $8.7 \%$ compared to experimental done by AyubJajja et al [13].

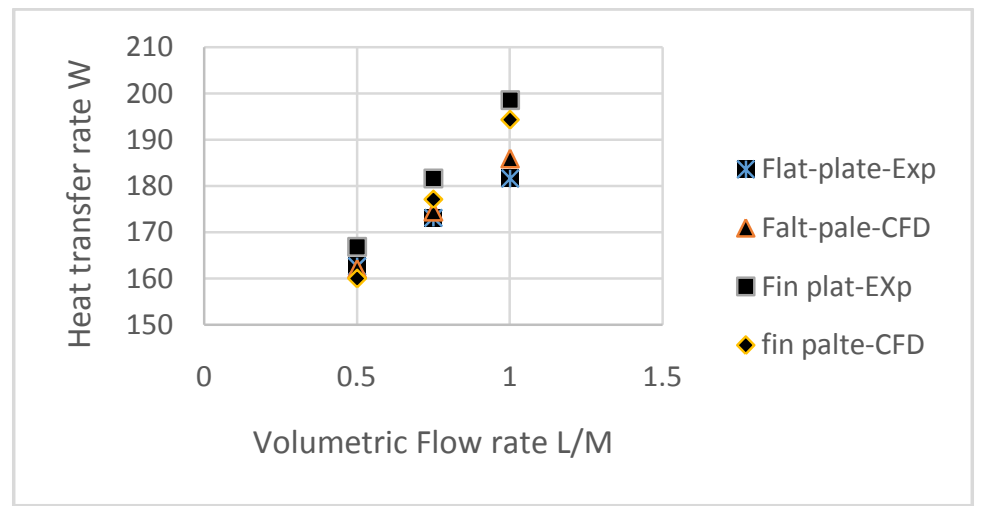

Figure 4: Comparisonofheattransferratewithvolumetric flow rate.

\subsection{Thermal resistance of heat sinks}

Fig. 3shows the change in thermal resistance with volume flow rate for both heat sinks. The thermal resistance for all heat sinks decreases by increasing the volumetric flow rate of water. The values of thermal resistance for flat plate heat sink geometry are considerably higher in comparison to the finned heat sink geometries. The maximum value of thermal resistance was found to be $0.214765 \mathrm{~K} / \mathrm{W}$ for flat plate heat sink at 0.5 LPM. The thermal resistance decreases by adding the fins for any given flow rate of the water. Heat sink with a fin spacing of $1.5 \mathrm{~mm}$ produced lowest value of thermal resistance of $0.067114 \mathrm{~K} / \mathrm{W}$ at a volume flow rate of 1 LPM.

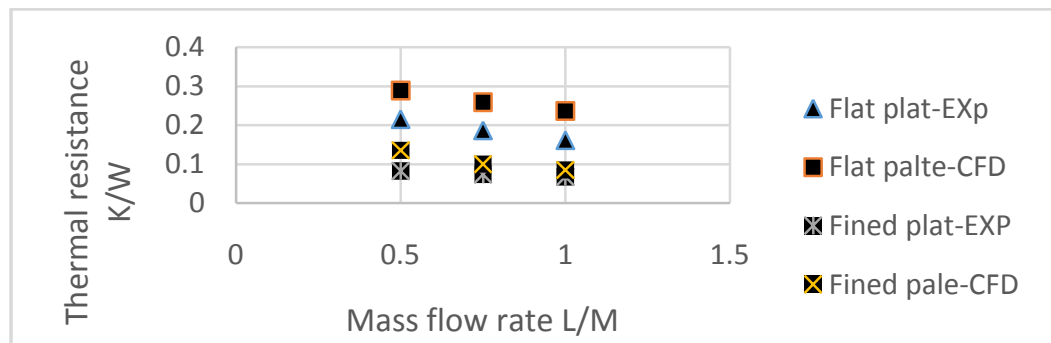

Figure 5:Variation of thermal resistance of heat sinks with volumetric flowrate. 


\section{Conclusion}

The effect of adding fins to a flat plate has been studied numerically.Two different heatsinks with finsalong with a flat plateheatsink were studied fo reffective thermal management of high heat generating device. At a simulated microprocessor power of 325

$\mathrm{W}$,thelowestheatsinkbasetemperatureof $51.7^{\circ} \mathrm{C}$ wasachievedbyusingaheatsinkof $1.5 \mathrm{~mm}$ finspacingataflowrateof 1 . Itcanbeconcludedfromthisnumericalstudythatgeometricallyenhancedheatsinksby using fins, have a lotofpotentialtomanagethehighheatgeneratingdevices.

\section{References}

[1]. T. H. Kim, K. H. Do and D.-K. Kim, "Closed form correlations for thermal optimization of plate-fin heat sinks under natural convection," International Journal of Heat and Mass Transfer , vol. 54, p. 1210-1216, 2011.

[2]. S.-C. Lin, F.-S. Chuang and C.-A. Chou, "Experimental study of the heat sink assembly with oblique straight fins," Experimental Thermal and Fluid Science 29 (2005) 591-600, vol. 29 , p. 591-600, 2005.

[3]. C.-C. Wang, K.-S. Yang, Y.-P. Liu and I. Y. Chen, "Effect of cannelure fin configuration on compact aircooling heat sink," Applied Thermal Engineering , vol. 31, pp. 1640-1647, 2011.

[4]. W. Pang, Y. Liub, S. Shao and X. Gao, "Empirical study on thermal performance through separating impacts from a hybrid PV/TE system design integrating heat sink," International Communications in Heat and Mass Transfer, vol. 60, p. 9-12, 2015.

[5]. H.-Y. Li and S.-M. Chao, "Measurement of performance of plate-fin heat sinks with cross flow cooling," International Journal of Heat and Mass Transfer, vol. 52, pp. 2949-2955, 2009.

[6]. Q. Shen, D. Sun, T. J. Ya Xu and X. Zhao, "Orientation effects on natural convection heat dissipation of rectangular fin heat sinks mounted on LEDs," International Journal of Heat and Mass Transfer, vol. 75, p. 462-469, 2014.

[7]. D. Jang, S.-J. Park, S.-J. Yook and K.-S. Lee, "The orientation effect for cylindrical heat sinks with application to LED light bulbs," International Journal of Heat and Mass Transfer, vol. 71, p. 496-502, 2014.

[8]. D.-K. Kim, "Thermal optimization of plate-fin heat sinks with fins of variable thickness under natural convection," International Journal of Heat and Mass Transfer, vol. 55, p. 752-761, 2012.

[9]. M. Sohel, S. Khaleduzzaman, R. Saidur, A. Hepbasli, M. Sabri and I. Mahbubul, "An experimental investigation of heat transfer enhancement of a minichannel heat sink using Al2O3-H2O nanofluid," International Journal of Heat and Mass Transfer, vol. 74, p. 164-172, 2014.

[10]. C. Ho and W. Chen, "An experimental study on thermal performance of Al2O3/water nanofluid in a minichannel heat sink," Applied Thermal Engineering, vol. 50, pp. 516-522, 2013.

[11]. S. M. H. Hashemi, S. A. Fazeli, H. Zirakzadeh and M. Ashjaee, "Study of heat transfer enhancement in a nanofluidcooled miniature heat sink," International Communications in Heat and Mass Transfer, vol. 39, p. 877-884, 2012.

[12]. A. H. M. N. M. Rafati, " Applications of nanofluids in computer cooling systems (heat transfer performance of nanofluids)," Appl. Therm. Eng, Vols. 45-46, pp. 9-14, 2012.

[13]. W. A. H. M. A. A. M. A. Saad Ayub Jajja a, "Water cooled minichannel heat sinks for microprocessor," Applied Thermal Engineering, vol. 64, pp. 76-82, 2014. 